\title{
ST
}

Science \& Technology

PAPER - OPEN ACCESS

\section{Penerapan POGIL Dengan LKS Dalam Meningkatkan Hasil Belajar pada Koloid Berbasis Lesson Study}

\author{
Author : Angeline Ayurosalia dkk., \\ DOI : :10.32734/st.v2i1.332 \\ Electronic ISSN $\quad: 2654-7082$ \\ Print ISSN : $2654-7074$
}

Volume 2 Issue 1 - 2018 TALENTA Conference Series: Science \& Technology (ST)

This work is licensed under a Creative Commons Attribution-NoDerivatives 4.0 International License.

Published under licence by TALENTA Publisher, Universitas Sumatera Utara

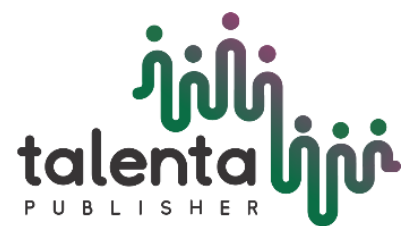




\title{
Penerapan POGIL Dengan LKS Dalam Meningkatkan Hasil Belajar pada Koloid Berbasis Lesson Study
}

\author{
Angeline Viska Ayurosalia ${ }^{\mathrm{a}^{*}}$, Zainuddin Muchtar ${ }^{\mathrm{b}}$, Febiana Wulandari $^{\mathrm{c}}$, Arfiena Fitria \\ Berutu $^{\mathrm{d}}$
}

${ }^{a}$ Program Studi Pendidikan Kimia, Pascasarjana, Universitas Negeri Medan, Medan

${ }^{b}$ Jurusan Kimia, Fakultas MIPA, Universitas Negeri Medan, Medan

angiepjt@mhs.unimed.ac.id

\begin{abstract}
Abstrak
Tujuan penelitian ini ialah untuk memperoleh perbandingan antara pembelajaran dengan penggunaan strategi POGIL dengan media LKS yang berbasis lesson study dengan pembelajaran konvensional. Penelitian ini dilangsungkan di 3 sekolah menengah atas di kota Medan antara lain SMA Negeri 2 Medan, SMA Negeri 3 Medan dan SMA Swasta Raksana. Populasinya merupakan seluruh siswa yang diambil secara acak. Pada penelitian ini menggunakan instrument tes yang sudah valid untuk melihat peningkatan hasil belajar siswa. Dalam analisis data digunakan SPSS-18. Berdasarkan hasil penelitian dapat dilihat bahwa strategi POGIL dengan media LKS berbasis lesson study memberi peningkatan terhadap hasil belajar siswa dibandingkan konvensional. Nilai gain pada kelas eksperiment lebih tinggi dibandingkan pada kelas control.
\end{abstract}

Kata kunci: POGIL; LKS; hasil belajar siswa; lesson study; koloid

\begin{abstract}
The objectives of this research are to get the comparison between POGIL strategy with worksheet media based on lesson study and direct instruction method to increase student's achievement. Beside of that, this research also conducted to know the correlation between student's achievement. This research was done in SMA Negeri 2 Medan, SMA Negeri 3 Medan and SMA Swasta Raksana. Population is all the students which taken by purposive random sampling. The research instruments are achievement test and have been validated. The research data analyzed by SPSS -18 for windows. The result data shows that The student's achievement taught by between POGIL strategy with worksheet media based on lesson study gives higher significance difference than direct instruction method. It can be seen from the gain value in experiment class is higher than control class.
\end{abstract}

Keywords: POGIL; Worksheet; lesson study; student's achievement; student's interest; colloidal system

\section{Pendahuluan}

Pendidikan sangatlah penting dalam kehidupan manusia karena pendidikan dapat meningkatkan kemampuan diri melalui proses pembelajarannya. Perkembangan pendidikan akan berpengaruh terhadap kemajuan bangsa. Perkembangan pendidikan di Indonesia sangatlah cepat dimana diperlukan untuk menghadapi persaingan global. Berdasarkan fungsinya, pedidikan bertujuan untuk meningkatkan kemampuan dan membentuk karakter melalui pembelajaran.

Hal-hal yang berperan dalam pendidikan ialah

a. Murid

b. Guru

c. Pengajaran interaktif dimana ada interaksi siswa dan guru

d. Tujuan pembelajaran [1]. 
Dalam proses belajar mengajar, guru memiliki andil penting. Guru yang kritis akan lebih menyukai metode discovery untuk mengajar siswanya dengan tujuan mereka dapat meningkatkan kemampuannya dalam menyelesaikan tugas yang diberikan guru. Guru akan lebih memprioritaskan proses belajar seperti merumuskan tujuan dari materi daripada penyelesaian masalah. Penguasaan materi merupakan kunci utama untuk siswa dalam melanjutkan pembelajaran selanjutnya.

Namun beberapa guru lebih memilih metode ceramah dan menekan siswa hanya untuk mendengar dan menerima pelajaran tanpa memberikan kesempatan kepada siswa untuk meneliti dan menyelesaikan masalah dengan pemikiran mereka sendiri. Guru seperti ini lebih mengutamakan hasil belajar dibandingkan prosesnya [2].

Pada umumnya, kegiatan belajar mengajar masih menggunakan metode ceramah dimana kurang bervariasi dan siswa cenderung bosan akan proses belajar karena kegiatan ini berpusat pada guru. Guru menjadi pusat pembelajaran dan mendominasi kegiatan belajar [3].

Pada metode ceramah, proses pembelajaran ditandai oleh guru mendominasi dan memberikan pembagian tugas kepada siswa. Metode ini mengakibatkan hasil belajar siswa cenderung rendah. Oleh sebab itu, maka guru perlu menggunakan metode pembelajaran lainnya untuk meningkatkan hasil belajar siswa.

Kimia merupakansalah satu mata pelajaran yang cenderung dinilai siswa terlampau sulit dikarenakan konsep abstraknya yang sulit untuk dipahami. Padahal kimia merupakan pengetahuaan dasar karena semua pengetahuan berlandaskan kimia. Umumnya siswa cenderung menghafal konsep abstrak dalam mempelajari kimia dibandingkan meneliti untuk meningkatkan kemampuan mereka dalam mempelajari kimia [4].

Agar proses belajar mengajar lebih menarik, maka aspek penting yang digunakan ialah strategi pembelajaran dan media yang berkaitan untuk meningkatkan hasil belajar siswa. Oleh sebab itu, untuk meningkatkan hasil belajar siswa guru hendaknya memilih strategi dan media pembelajaran [5].

Pembelajaran Kimia sampai saat ini masih merupakan tantangan besar bagi pengajar. Kimia dipandang siswa ebagai mata pelajaran yang sulit. Materi dalam mata pelajaran kimia yang dianggap sulit untuk dipahami ialah Koloid.

Strategi yang dapat digunakan untuk memfasilitasi dan melatih kreativitas siswa selama proses pembelajaran ialah Process Guided Inquiry Learning (POGIL). POGIL merupakan salah satu strategi pembelajaran yang berpusat pada proses kemampuan dengan pendekatan inkuiri, yang terdiri dari fase eksplorasi, discovery dan aplikasi. POGIL merupakan sebuah proses pembelajaran yang berdasarkan pada prinsip konstrukvisme dimana siswa mampu dalam pembelajaran melalui interaksi grup dalam pemecahan masalah. POGIL dapat digunakan untuk latihan terstruktur, latihan kelompok dimana siswa diberikan tugas dan dibimbing melalui tahapan yang memerlukan penyelesaian masalah [6].

Kegiatan aktivitas dalam strategi POGIL disertai kemampuan siswa dalam melihat dan menginvestagasi secara sistematis dan kritis, logika, analisis agar siswa mampu menarik kesimpulan dengan maksimal dan percaya diri [7].

Pada penelitian yang dilakukan oleh Silvia (2014) dimana strategi POGIL dengan menggunakan media powerpoint dapat meningkatka hasil belajar siswa, menunjukkan hasil belajarnya $78 \%$. Penelitian yang dilakukan oleh Sri Wahyuna Saragih menunjukkan nilai gain hasil belajar sebesar $72 \%$ dan pada penelitian yang dilakukan oleh Tukma Sari menunjukkan nilai gain hasil belajar sebesar $84 \%$.

Lembar Kerja Siswa (LKS) dapat menjadi media alternatif yang dapat digunakan pada proses pembelajaran karena dapat meningkatkan pemahaman konsep karena LKS disusun untuk membimbing siswa dalam proses pembelajaran materi.

Lesson study melibatkan guru dalam kelompok diskusi dengan aktivitas sebagai berikut ini, merancang proses pembelajaran, observasi pembelajaran dan mendiskusikan setelah proses pembelajaran guna meningkatkan proses pembelajaran berikutnya [8].

Berdasarkan hasil observasi ketika melakukan PPL dimana kebanyakan siswa kelas XI IPA di SMAN 1 Berastagi mendapat nilai rendah pada pelajaran kimia. Pada umumnya, siswa menganggap pelajaran kimia sulit untuk dipelajari, dan sulit mengaitkan dengan kehidupan sehari-hari.

Koloid merupakan salah satu topik pelajaran kimia kelas XI yang memerlukan pemahaman siswa yang tinggi. Darri berbaai masalah dapat disimpulkan bahwa kesulitan siswa dalam pemahaman konsep disebabkkan oleh beberapa faktor yaitu cara guru mengajar, strategi pembelajaran dan media yang digunakan.

Strategi POGIL dan media LKS digunakan pada penelitian ini ialah untuuk meningkatkan hasil belajar siswa melalui kolaborasi dalam kerja kelompok, fokus pada proses pembelajaran. 


\section{Metode}

Populasi dan Sampel. Penelitian ini dilakukan di SMA Negeri 2 Medan, SMA Negeri 3 Medan SMA Swasta Raksana dengan populasi siswa kelas XI. Sampel diambil secara purposive dan diambil dua kelas dalam penelitian ini dimana kelas pertama sebagai kelas eskperimen dan kelas control. Masing-masing kelas terdiri dari 30 siswa. Pada kelas control digunakan metode pembelajaran konvensional dan pada kelas eksperimen digunakan strategi POGIL dengan media LKS berbasis lesson study.Pada penelitian ini bertujuan untuk melihat peningkatan hasil belajar siswa dengan menggunakan strategi POGIL dengan media LKS berbasis Lesson study.

Prosedur Penelitian. Pada awal pelajaran, identifikasi masalah dengan strategi POGIL dan LKS. LKS disusun berdasarkan metode POGIL yang ditandai dengan adanya pertanyaan-pertanyaan yang membimbing siswa untuk menemukan konsepnya. POGIL juga menunjukkan rencana pembelajaran dan aktivitas pembelajaran dimana memiliki fase-fase antaranya eksplorasi,formasi dan aplikasi. Lalu siswa dibagi dalam beberapa kelompok belajar. Pembelajaran dengan topik Koloid diawal dengan pengenalan sistem koloid itu sendiri, pada fase orientasi, guru memotivasi dan mempersiapkan siswa untuk belajar koloid. Pengelompokkan aktivitas POGIL berdasarkan pada model aktivitas didalam buku pembelajaran dan LKS yang telah disusun. Pada fase eksplorasi, siswa dibimbing dan dimonitor oleh siswa dalam aktivitas, siswa juga mengumpulkan data dan menguji hipotesis tersebut. Pada fase formasi, guru juga membantu siswa dalam menemukan konsep tentang koloid. Pada fase aplikasi, siiswa yang telah paham akan konsep koloid diberikan pertanyaan yang didiskusikan dalam kelompok ataupun individu. Pada fase akhir, siswa menampilkan dan mengevaluasi hasil pelajaran.

Instrumen yang digunakan.Instrumen yang digunakan pada penelitian ini ialah untuk mengukur aspek kognitif dengan memberikan pretest dan posttest dan diproses menggunakan SPSS 18.

\section{Hasil dan pembahasan}

\section{Hasil pretest dan posttest}

Pretes diberikan sebelum penerapan dari perlakuan dalam proses pembelajaran dikedua kelas. Tujuannya untuk mengetahui pengetahuan dasar siswa mengenai koloid. Data yang diperoleh dari pretest dapat digunakan untuk menjelaskan uji normalitas dan homogenitas. Post test diberikan setelah penerapan perlakuan dikedua kelas, dimana kelas eksperimen diajarkan dengan strategi POGIL dengan media LKS berbasis lesson study dan kelas control dengan menggunakan metode konvensional. Data yang diperoleh dari pretest dan posttest dapat dilihat ada table 1.

Tabel 1. Data Pretest dan Posttest

\begin{tabular}{|c|c|c|c|c|c|}
\hline \multirow[t]{2}{*}{ Sampel } & \multirow[t]{2}{*}{ Sekolah } & \multicolumn{2}{|c|}{ Pretest } & \multicolumn{2}{|c|}{ Posttest } \\
\hline & & Mean & SD & Mean & SD \\
\hline \multirow[t]{4}{*}{ Eksperimen } & SMAN 2 Medan & 33.83 & 10.06 & 81.17 & 12.91 \\
\hline & SMAN 3 Medan & 39.17 & 6.96 & 91.33 & 5.71 \\
\hline & SMA Swasta Raksana & 39.67 & 9.64 & 83.17 & 7.6 \\
\hline & TOTAL & 37.56 & 1.68 & 85.22 & 3.73 \\
\hline \multirow[t]{4}{*}{ Kontrol } & SMAN 2 Medan & 29 & 10.29 & 67.83 & 8.97 \\
\hline & SMAN 3 Medan & 28.67 & 8.6 & 70.5 & 7.47 \\
\hline & SMA Swasta Raksana & 38.17 & 8.56 & 73.33 & 9.59 \\
\hline & TOTAL & 31.95 & 0.99 & 70.55 & 1.09 \\
\hline
\end{tabular}

Berdasarkan table 1 nilai rata-rata pretest yang diperoleh dikelas control dari ketigas sekolah tersebut adalah (31.95 \pm 0.09$)$ dimana SMA Swasta Raksana memperoleh nilai tertinggi (38.17 \pm 8.56$)$ dan terendah diperoleh SMAN 3 Medan (28.67 \pm 8.6$)$.Nilai rata-rata pretest dikelas eksperimen pada ketiga sekolah tersebut adalah (37.56 \pm 1.68) dimana SMA Swasta Raksana memperoleh nilai tertnggi (39.67 \pm 9.64$)$ dan SMAN 2 Medan (33.83 \pm 10.06$)$. Nilai posttest pada kelas eksperimen dari ketiga sekolah itu adalah $(85.22 \pm 3.73)$ dimana SMAN 3 Medan memperoleh nilai tertinggi $(91.33 \pm 5.71)$ dan yang terendah di SMAN 2 Medan $(81.17 \pm 12.91)$.Nilai rata-rata posttest pada kelas control di ketiga sekolah tersebut adalah (70.55 \pm 1.09$)$, dimana SMA Swasta Raksana memiliki nilai tertinggi (73.33 \pm 9.59$)$ dan terendah di SMA N 2 Medan (67.83 \pm 8.97$)$ 


\section{Hasil Belajar Siswa Sebelum Diberi Treatment.}

Sebelum memberikan treatment pada kelas eksperimen dan kelas control ada baiknya kita memberikan pretes dimana untuk menguji pengetahuan siswa akan topik koloid. Data yang diperoleh sebagai berikut ini :

Tabel 2. Nilai Pretest

\begin{tabular}{llcc}
\hline Sampel & Sekolah & \multicolumn{2}{c}{ Pretest } \\
\cline { 2 - 4 } Eksperimen & SMAN 2 Medan & Mean & 10.06 \\
& SMAN 3 Medan & 33.83 & 39.17 \\
\hline SMA Swasta Raksana & 39.67 & 9.96 \\
\hline Kontrol & TOTAL & 37.56 & 1.68 \\
& SMAN 2 Medan & 29 & 10.29 \\
\hline & SMAN 3 Medan & 28.67 & 8.6 \\
\hline
\end{tabular}

Dari data tersebut dapat dilihat bahwa hasil belajar siswa di ketiga sekolah tersebut masih sangat rendah, semua kelas memiliki rata-rata nilai yang rendah dikarenakan siswa belum pernah mempelajari topik koloid. Nilai pretest yang diperoleh pada kedua kelas adalah sama.

\section{Hasil Belajar Siswa Setelah Treatment.}

Setelah memberikan treatment dikedua kelas, maka diberikan posttest untuk melihat peningkatan hasil belajar siswa. Kedua kelas diberikan strategi pembelajaran yang berbeda. Sehingga diperoleh hasil sebagai berikut ini :

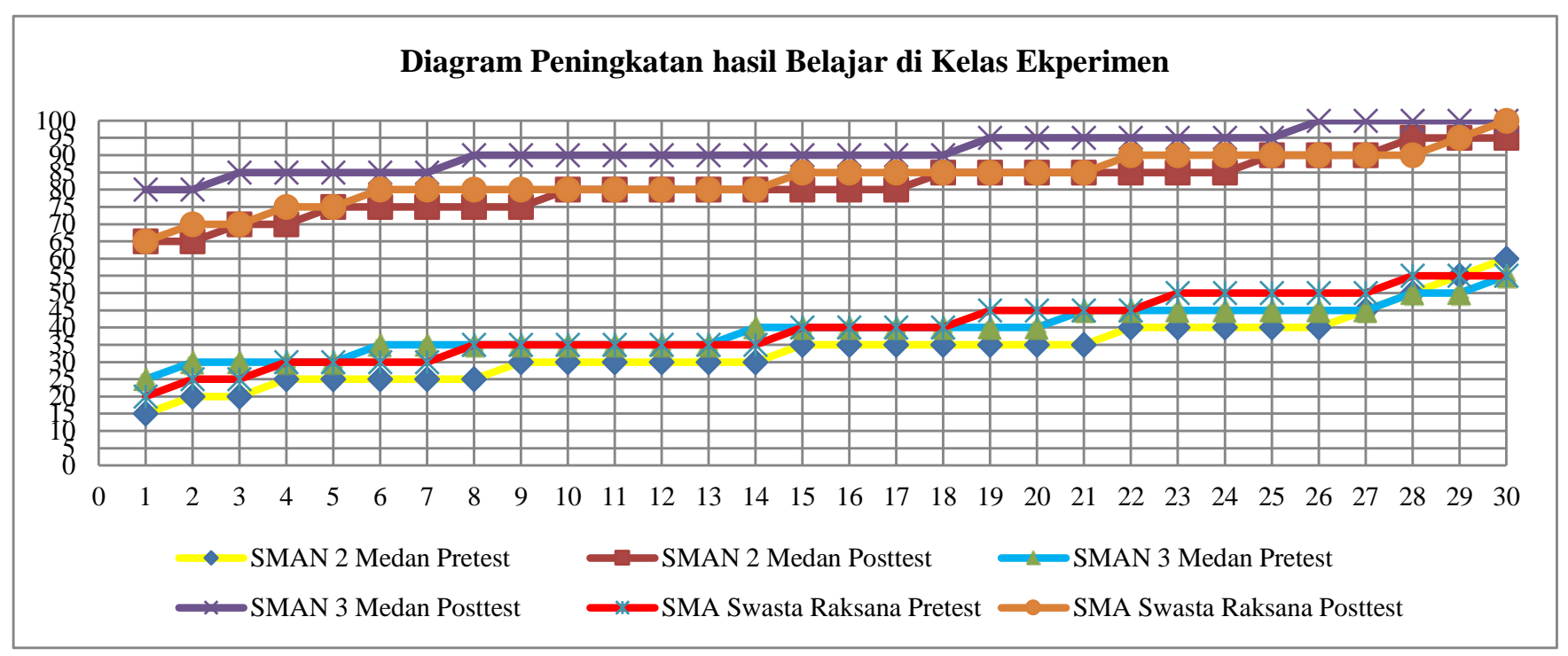

Gambar 1. Peningkatan Hasil Belajar Siswa pada Kelas Eksperiment 


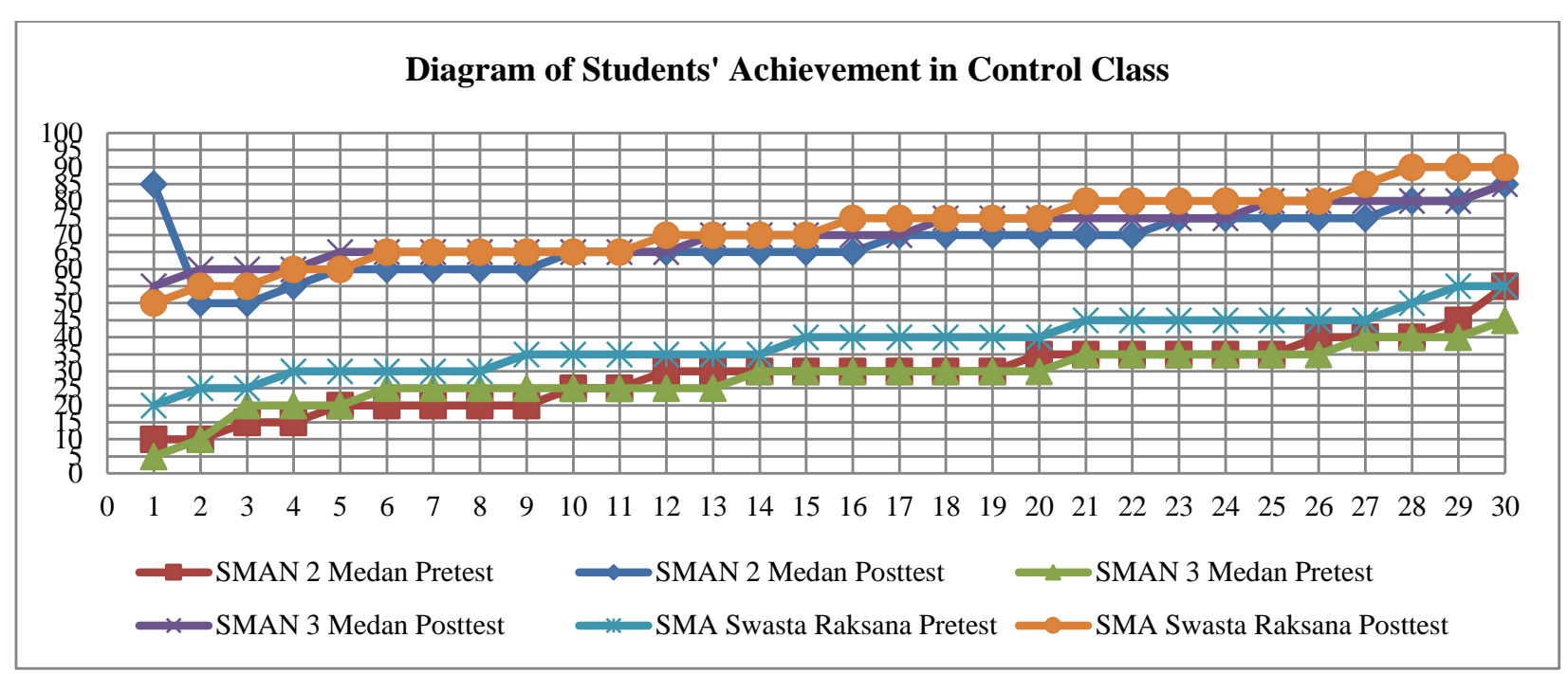

Gambar 2. Peningkatan Hasil Belajar Pada Kelas Kontrol

Uji Gain. Nilai Pretest dan Posttest akan digunakan untuk normalitas gain terhadap hasil belajar siswa. Normalitas gain akan ditunjukkan sebagai perbandingan hasil belajar siswa pada kedua kelas yang diberikan perlakuan berbeda. Nilai tersebut ditunjukkan pada table berikut ini :

\begin{tabular}{|c|c|c|c|c|c|}
\hline \multirow[t]{2}{*}{ Sampel } & \multirow[t]{2}{*}{ Sekolah } & \multicolumn{2}{|c|}{ Gain } & \multirow[t]{2}{*}{$\%$ Gain } & \multirow[t]{2}{*}{ Kategori Gain } \\
\hline & & Mean & SD & & \\
\hline \multirow[t]{4}{*}{ Eksperimen } & SMAN 2 Medan & 0.71 & 0.13 & $71 \%$ & High \\
\hline & SMAN 3 Medan & 0.86 & 0.09 & $86 \%$ & High \\
\hline & SMA Swasta Raksana & 0.72 & 0.12 & $72 \%$ & High \\
\hline & TOTAL & 0.76 & 0.02 & $76 \%$ & \\
\hline \multirow[t]{4}{*}{ Kontrol } & SMAN 2 Medan & 0.54 & 0.11 & $54 \%$ & Medium \\
\hline & SMAN 3 Medan & 0.58 & 0.11 & $58 \%$ & Medium \\
\hline & SMA Swasta Raksana & 0.56 & 0.18 & $56 \%$ & Medium \\
\hline & TOTAL & 0.56 & 0.13 & $56 \%$ & \\
\hline
\end{tabular}

Dari data tersebut diperoleh rata-rata nilai gain dikelas eksperimen pada ketiga sekolah tersebut adalah $(0.76 \pm 0.02)$ dimana SMAN 3 Medan memperoleh nilai tertinggi dan SMAN 2 Medan memperoleh nilai terendah sedangkan rata-rata gain pada kelas control diketiga sekolah tersebut adalah $(0.56 \pm 0.04)$ dimana SMAN 3 memperoleh nilai gain tertinggi dan SMAN 2 Medan nilai gain terendah. Jadi, nilai pada kelas eksperimen dari ketiga sekolah tersebut lebih tinggi dibandingkan nilai pada kelas control.

\section{Kesimpulan}

Berdasarkan hasil analisis data maka dapat diperoleh bahwa siswa diajarkan dengan menggunakan strategi POGIL dengan media LKS berbasis Lesson Study memberikan peningkatan hasil belajar yang tinggi dibandingkan dengan menggunakan metode konvensional. Strategi POGIL dan media LKS dapat digunakan oleh guru dalam pelajaran kimia khususnya materi Koloid yang dapat diintegrasikan dengan kehidupan nyata.

\section{Referensi}

[1] Tirtarahardja, U.,(2005), Pengantar Pendidikan, PT Rineka Cipta, Jakarta.

[2] Sudjana,(2009), Hasil belar Siswa dalam Proses Pembelajaran di Kelas, Balai Pustaka, Jakarta

[3] Ruseffendi, E.T.,(1974), Dasar-Dasar Matematikan modern: Untuk Guru, IKIP Bandung, Bandung.

[4] Sanjaya, W.,(2008), Perencanaan dan Desain Sistem Pembelajaran, Kencana Prenada Media Group, Jakarta

[5] Arsyad, A., (2011), Media Pembelajaran, Rajawali Pers, Jakarta. 
[6] Erick, M., and Derrik, H., (2010), Using POGIL Techniques in an Information Literacy Curriculum, The Journal Of Academic Librarianship36 (6) : 539-542

[7] Moog, R. S., Spencer, J., (1999), A Guided Inquiry General Chemistry Course. J. Chem. Educ. 76: 570-574 